\title{
Spatial difference and mechanisms of influence of geo-economy in the border areas of China
}

\author{
SONG Tao ${ }^{1,2,3},{ }^{*}$ CHENG Yi ${ }^{1,2,4}$, LIU Weidong ${ }^{1,2}$, LIU Hui ${ }^{1,2,4}$ \\ 1. Key Laboratory of Regional Sustainable Development Modeling, CAS, Beijing 100101, China; \\ 2. Institute of Geographic Sciences and Natural Resources Research, CAS, Beijing 100101, China; \\ 3. Collaborative Innovation Center for Geopolitical Setting of Southwest China and Borderland Development, \\ Kunming 650500, China; \\ 4. College of Resources and Environment, University of Chinese Academy of Sciences, Beijing 100049, China
}

\begin{abstract}
Border areas are both important territorial security barriers and portals to the outside world. Considering the complicated geopolitical environment of China's inland borders, analysis of the current status and mechanisms of influence of geo-economy in border areas is of great significance. Namely, this analysis is important towards leveraging traditional advantages to accelerate China's development in border and minority areas. Based on a comprehensive analysis, our study constructed a framework to analyze the geo-economy in border areas, and also introduced three indexes: local economy, export-oriented economy and local development. In addition, our study systematically described geo-economic evolution in the border areas of China. We also analyzed the mechanism of geo-economic spatial differentiation in these border areas by using geographical detectors. Our results indicated that the level of geo-economic influence in border areas has grown steadily with significant spatial differentiation. The absolute geo-economic dominance of Northeast China gradually declines over time. Areas with geo-economic advantages are highly dispersed, showing a spatial polarization pattern with several polar nuclei including Mudanjiang city (Northeast China), Baotou city (Inner Mongolia), Bortala Mongol Autonomous Prefecture (Xinjiang), Dehong Dai and Jingpo Autonomous Prefecture and the city of Chongzuo (Yunnan-Guangxi area). Geo-economics in border area is mainly influenced by national policies, the development level of neighboring countries, as well as the desire of these countries to cooperate with China in bilateral trade. Favorable policies, traffic, cultural proximity and other factors also impact the geo-economics of border areas significantly. The Inner Mongolia and Tibet areas are mainly influenced by neighboring countries, while Northeast China and Xinjiang are mainly affected by Chinese policies; the Yunnan-Guangxi area is influenced by a combination of these factors. At the end of the study, we provide our recommendations for developing policies that further geo-economic advantages in complex geopolitical environments and in areas with varied development.
\end{abstract}

Received: 2017-03-12 Accepted: 2017-05-10

Foundation: National Natural Science Foundation of China, No.41701131, No.41530634; Key Consulting Project of the Chinese Academy of Science and Technology Strategic Consulting, No.Y02015001; Funding of Institute of Geographic Sciences and Natural Resources Research, CAS, No.Y55R1203YZ

Author: Song Tao (1983-), PhD, specialized in geopolitics and regional sustainable development.

E-mail:songtao@igsnrr.ac.cn

"Corresponding author: Cheng Yi (1992-), MS, specialized in regional development. E-mail: chengy.14s@igsnrr.ac.cn. 
Keywords: border area; geo-economy; geopolitics; geography detector

\section{Introduction}

For any country, border areas are both important barriers for territorial security and portals to the outside world. With shifts in world order and the emerging power of globalization, China's administrative divisions in border areas are pivotal to geopolitical territorial disputes as well as geopolitical cooperation ( $\mathrm{Lu}$ and $\mathrm{Du}, 2013$ ). The socio-economic development and territorial security of border areas have increasingly become prominent issues of human geography and geopolitics, among other disciplines of research (Newman and Paasi, 1998). China has a land border of 22,000 kilometers, encompassing 14 countries including Russia, Mongolia, Kazakhstan, India, and Myanmar. In general, these countries are geopolitically complicated, highly fragmented, and vastly different in terms of economic development as well as political system and ideology. Wrestling in border areas is central to displays of power and a key area for China's contemporary geopolitical strategy (Song et al., 2016). Meanwhile, the border provinces located in the central and western regions as well as Northeast China are generally characterized as "ethnic minority areas, border areas and impoverished areas". Territorial and national power in the geopolitical perspective is always a critical aspect of border research. Since the start of the 21 st century, border research has developed the essence of critical geopolitics and humanistic geopolitics, and gradually strengthened reflection on border environments and social governance. Border areas have become classic cases used in research studying spatial changes and their influence (Tang et al., 2016). Scholars have examined the process of opening and developing border areas from the aspects of economic and trade industries, population migration, and border security, with a particular focus on national interests in border security and development ( $\mathrm{Su}, 2013$; Luo and $\mathrm{Li}, 2010$ ). In general, the research described above delineates the structural characteristics of economic, social, and cultural development in border areas, with special attention given to the discussion of patterns found across individual cases. However, it is still rare to find discussions surrounding spatial pattern and distribution difference of China's land border areas from a macroscopic point of view. In particular, research is still lacking on the "One Belt, One Road" and "Opening-up the Borders" policies in border areas.

Since the end of the Cold War, geopolitics has been redirected from spatial conflicts and power balance to geo-economics instead (Parker, 1998; Nye, 2004; Song et al., 2016). Geo-economic theory is an interdisciplinary principle that combines geographical, political economic and economic theories. It seeks the greatest benefits for countries by studying the interactions between politics and economy within a specific spatial scope (Gao, 2008; Yu and Fan, 2009; Xiong and Wang, 2012). It was originally proposed by Edward N. Luttwak (Luttwak, 1990), an American scholar, who has emphasized the presence of economic activities under the influence of geographical factors. During the development of geo-economics, various schools of thought representing different nations' characteristics gradually formed: American schools emphasized market control and economic competition; Russian schools focused on research of the nation's strategies; Italian schools concentrated on international competition and cooperation (Li et al., 2014). Although the focuses are different, the different schools of thought all arrive at a common post-Cold War consensus: in 
sharp contrast to "fighting, controlling and containment" during the Cold War, the era of geo-economics proposed "opening, collaboration, win-win, development" as the consensus. The post-Cold War era of geo-economics emphasized international dialogue as well as collaboration in broad fields including economic trade, industrial collaboration, population flow, cross-border safety, and environmental governance. Geo-economics is the product of geopolitics in certain historical phases (Li, 2006; Pan and Huang, 2008; Li, 2008; Huang, 2011), and also the result of regional economic integration and globalization that serve country interests (Cui, 2004). Geopolitical research aims to construct a national interest-based geo-economic strategy by studying the geo-environment and utilizing geographical and cultural proximity. The mutual benefits in geo-economics can be achieved through control and collaboration of key factors including resources, trade, industry, market, capital, and infrastructure, and also through the construction of open platforms such as ports, strategic passages, border cooperation areas, and comprehensive bonded zones (Gao, 2009; Wang and Li, 2009). Geo-economics is an important driving force for border area development. The unique location of borders determines their unique developmental path by geo-economic cooperation under the premise of territorial security (Sit, 1998). Economic and trade cooperation, cultural communication, and the resulting spatial integration are the main manifestations of border geo-economics (Brunet-Jailly, 2005; Feng and Ding, 2005). The development of border regions is accelerating, riding on the wave of geo-economics, and will gradually break away from traditional border bartering and converting towards an open model of trans-border cooperation (Ratti, 1993; Sklair, 1993). The USA-Mexico border, USA-Canada border, and borders within the European Union represent regions of geo-economic cooperation. The development and cooperation zones in border areas are increasingly influenced by regional integration (Hanson, 1998), and attract a large number of enterprises (Venables, 1996; Hu et al., 2013).

Under economic globalization, China's economic opening and transition, and the complex geopolitical environment, it is important to comprehensively examine the spatial development structure of China's land border area geo-economics, and to analyze the internal mechanisms which support advantageous geo-economic development. Revealing the pattern of border development under the guidance of the "One Belt, One Road" national strategy is of great theoretical and practical importance for border opening and the building of a harmonious surrounding environment. Therefore, based on the theories of geopolitics and economic geography, this study analyzed the spatio-temporal differentiation and mechanisms of geo-economics in China's border areas under the "Belt and Road Initiative". The goal of this study is to provide a decision-making reference for geopolitical security and sustainable development in border areas.

\section{Data sources and research methods}

\subsection{Research area profile}

The land border areas of China, for which the prefecture-level cities are used as study units, include 45 prefecture-level administrative areas (Figure 1). The land of border areas occupies a large proportion, while the population and economy occupy a much smaller share (Table 1). 


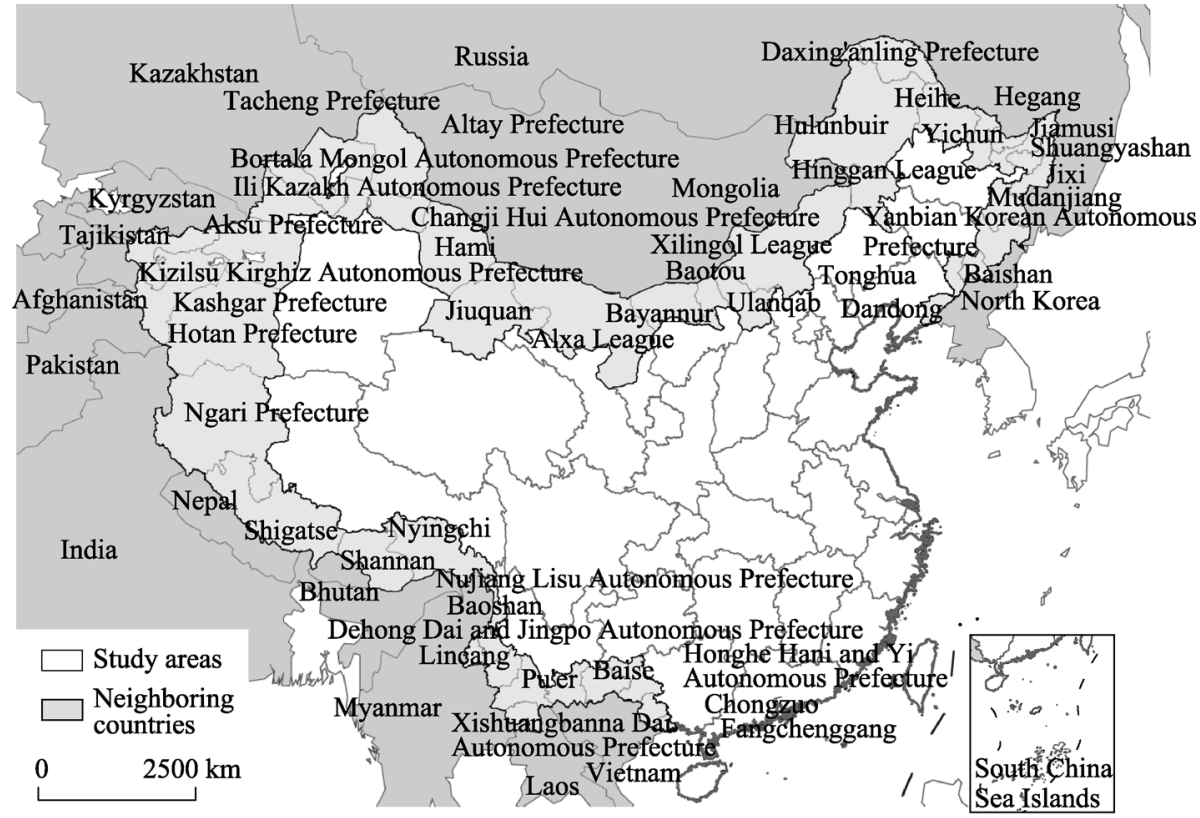

Figure 1 The land border areas of China.

Table 1 The general situation in the border areas of China in 2014

\begin{tabular}{lcccccc}
\hline & $\begin{array}{c}\text { Land } \\
\left(10^{4} \mathrm{~km}^{2}\right)\end{array}$ & $\begin{array}{c}\text { Percentage of } \\
\text { border areas }(\%)\end{array}$ & $\begin{array}{c}\text { Population } \\
\left(10^{4} \text { people }\right)\end{array}$ & $\begin{array}{c}\text { Percentage of } \\
\text { border areas }(\%)\end{array}$ & $\begin{array}{c}\text { GDP } \\
\left(10^{8} \text { yuan }\right)\end{array}$ & $\begin{array}{c}\text { Percentage of } \\
\text { border areas }(\%)\end{array}$ \\
\hline Border areas & 382 & 100 & 7785 & 100 & 28,583 & 100 \\
Nine border provinces & 593.19 & 64.4 & 28,156 & 27.6 & 120,758 & 23.7 \\
West China & 687.97 & 55.5 & 36,839 & 21.1 & 138,099 & 20.7 \\
All of China & 963.43 & 39.7 & 136,782 & 5.7 & 643,974 & 4.4 \\
\hline
\end{tabular}

\subsection{Data source}

Our research data was obtained mainly from the China Statistical Yearbook for Regional Economy. Data from the statistical yearbooks of the 9 provinces along the borders and prefecture-level cities, as well as the Statistical Communique of National Economy and Social Development published on the municipalities' websites of prefecture-level cities were used as supplementary material. Data regarding neighboring countries was obtained from the World Bank. Demographic data were mainly obtained from the 5th and 6th national population censuses.

\subsection{Theoretic framework of geo-economics}

Geo-economics is defined as a set of activities that seek regional economic development and political interest with the help of geographic location in a designated area. Therefore, its measurement index system needs to incorporate multiple factors. The selection of indicators for measuring the geo-economy in border areas should not only satisfy the demand for an export-oriented economy on the national level, but also take into account key elements of regional development for foreign trade, industries and facilities, among others. Currently, most academic measurement methods adopt the Euclidean Distance Method from the multi-factor analysis (Wen, 1998). The selected indicators normally include the percentage 
of fixed asset investment in the GDP, the percentage of wages of employees in the GDP, the percentage of agricultural output in industrial output, and so forth (Ding and Yu, 2008; Jin and $\mathrm{Du}, 2004$; Liu and Tu, 2011). Indicators used to evaluate the geo-economy include domestic investment, foreign investment, GDP, per capita GDP, industrial structure, labor force structure, technological investment and output, market opportunities, total exports, cultural proximity, national vulnerability, and political risk (Yang et al., 2016; Kuang-Hann, 2011; Buckley et al., 2007). One can observe that research on the geo-economy mainly selects indicators that represent local economic development and that are related to the economic environment such as political stability, spatial distance, and cultural fusion between countries. Based on the theoretical basis of geo-economics and China's direct foreign investments, and with the help of results from previous studies, this study constructs the measure index system for geo-economic development levels in border areas from the aspects of local economy, export-oriented economy and local comprehensive development (see Table 2). Local economic strength determines the depth and breadth of geo-economic development. This is represented by four indicators: per capita GDP, per capita local revenue, fixed asset investment, and year-end financial account balances. Export-oriented economy is the direct representation of geo-economic positioning. In this study, the total value of imports and exports, the level of dependence on foreign trade, foreign exchange earnings from tourism, and the dependence on foreign investment are selected as indicators to measure the export-oriented economy. These indicators are also used to represent the level of foreign trade activity in border areas and the ability to attract foreign investment. Local comprehensive development reflects the basic conditions for carrying out geo-economic activities. The number of employees, average salary, business volume of postage and telecommunications, and total mileage of highways are used as indicators to measure the local comprehensive developmental conditions, and to reveal differences in the fundamental environment that the geo-economy can develop.

Table 2 The comprehensive measure index system of the geo-economy in the border areas of China

\begin{tabular}{llc}
\hline \multicolumn{1}{c}{ System level } & Index strata & Weight \\
\hline Local economy (0.311) & Gross domestic product (GDP) per capita (yuan) & 0.082 \\
& Local public revenue per capita (yuan) & 0.073 \\
& Investments for fixed asset $\left(10^{8}\right.$ yuan) & 0.102 \\
& Year-end balance in financial institutions $\left(10^{8}\right.$ yuan) & 0.054 \\
Export-oriented economy & International trade (ten thousand dollars) & 0.107 \\
$(0.405)$ & Foreign trade dependence ratio $(\%)$ & 0.111 \\
& International tourism revenue $\left(10^{4}\right.$ dollars) & 0.084 \\
& Foreign capital reliance $(\%)$ & 0.103 \\
Local comprehensive & Employees $\left(10^{4}\right.$ people) & 0.057 \\
development $(0.284)$ & Average wage (yuan) & 0.042 \\
& Total business volume of post and telecommunications $\left(10^{8}\right.$ yuan $)$ & 0.101 \\
& Highway mileage percentage $\left(\mathrm{km} / \mathrm{km}^{2}\right)$ & 0.084 \\
\hline
\end{tabular}

\subsection{Analytic Hierarchy Process (AHP) entropy method for geo-economic indexes}

The entropy method is used in this paper to determine the weight of different indexes. Entropy is a physics concept that is also applied in the social sciences to reflect the measure of 
uncertainty in a system. The weight of indexes is calculated based on the value of entropy, namely, the variation of multiple indexes (Chen et al., 2009). The entropy method is used to calculate the comprehensive level of geo-economic development. Range standardization is performed on 14 indexes, which include 2816 data items from the years 2000, 2005, 2010 and 2014. Economic indexes are unified and converted to the 2000 level. The formula for this calculation is described below:

$$
Z_{i j}=\frac{x_{i j}-\min \left\{x_{i j}\right\}}{\max \left\{x_{i j}\right\}-\min \left\{x_{i j}\right\}}
$$

The national vulnerability index is a reverse index, and the standardization is performed as follows:

$$
Z_{i j}=\frac{\max \left\{x_{i j}\right\}-x_{i j}}{\max \left\{x_{i j}\right\}-\min \left\{x_{i j}\right\}}
$$

where $X_{i j}$ stands for the value of the $j$ th indicator in region $i$. They are the minimum and maximum value of the $j$ th indicator in the $i$ th region.

To calculate the weight of the $j$ th indicator in the $i$ th region:

$$
Y_{i j}=\frac{Z_{i j}}{\sum_{j=1}^{m} Z_{i j}}
$$

Calculation for index of information entropy:

$$
e_{j}=-k \sum_{i=1}^{m}\left(y_{i j} \times \ln y_{i j}\right), k=\frac{1}{\ln m}
$$

Information redundancy:

$$
d_{j}=1-e_{j}
$$

The weights of the indexes:

$$
w_{j}=\frac{d_{j}}{\sum_{j=1}^{n} d_{j}}
$$

The comprehensive evaluation index of the geo-economy is calculated. Based on the weights and the standardized value of each index, the calculation of the geo-economic development level of area $i$ is:

$$
S_{j}=w_{j} \times Z_{i j}
$$

Our study modified the weight of entropy method by consulting experts and combining Analytic Hierarchy Process (AHP). The weights obtained for comprehensive indexes of the geo-economy in the border areas of China are described in Figure 2.

\subsection{Geographical detectors}

Taking into consideration the developmental level and mechanisms of influence on geo-economics, we generated influencing factors for the comprehensive development level of geo-economics in border areas, shown in Table 3. Since geopolitics are difficult to quantify, this study only measured the State Fragility Index and Cultural Similarity Index. The State Fragility Index, also known as the Political Stability Index, is calculated by the Center 

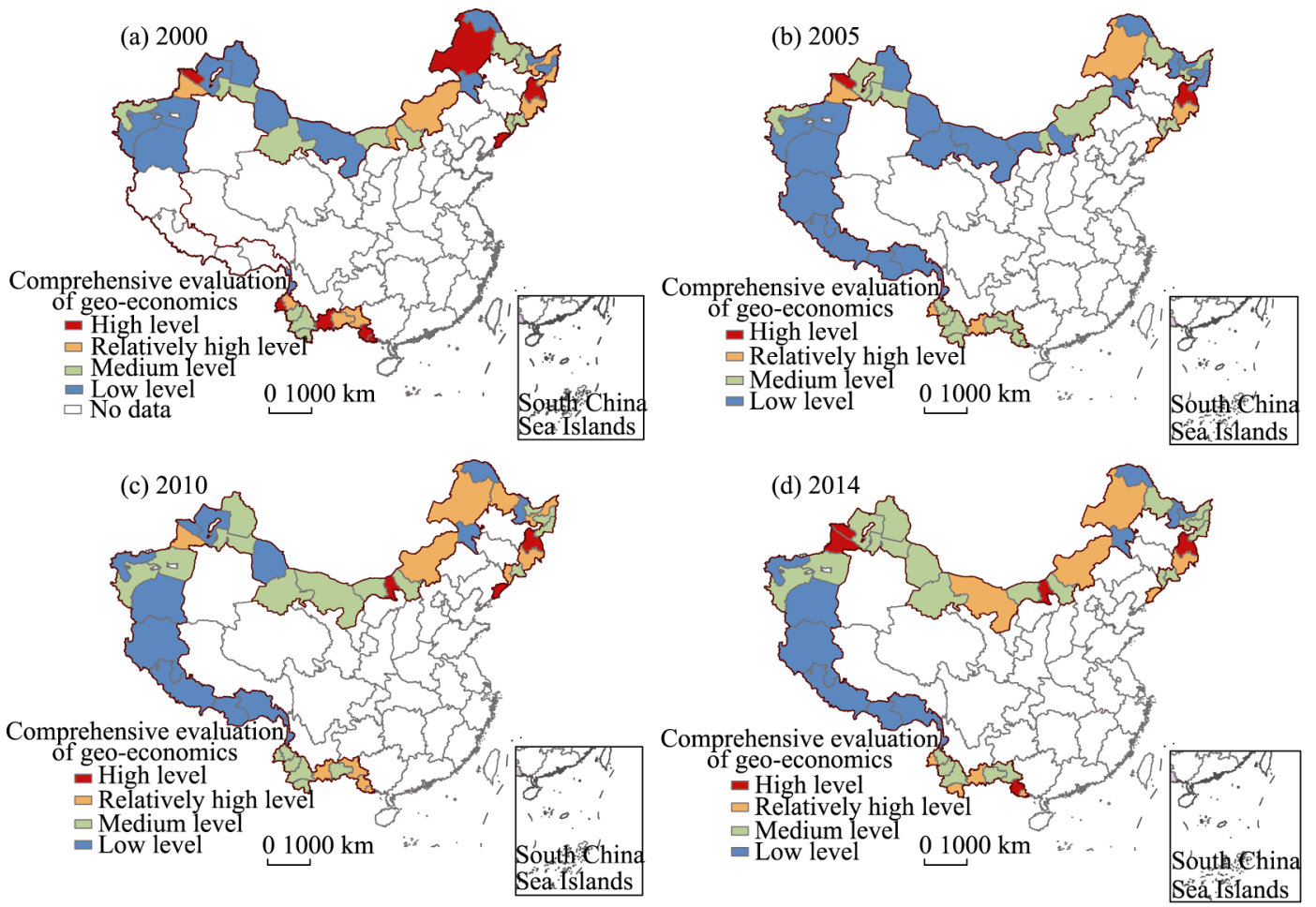

Figure 2 Comprehensive evaluations of geo-economic development in the border areas of China

Table 3 Factors influencing the geo-economy in the border areas of China

\begin{tabular}{|c|c|c|c|}
\hline Index & Explanation of the index & Data source & $\begin{array}{l}\text { Influence of } \\
\text { the index }\end{array}$ \\
\hline State fragility index & $\begin{array}{l}\text { Capacity of the country to resist } \\
\text { international conflicts and violence }\end{array}$ & CSP & - \\
\hline $\begin{array}{l}\text { Cultural Similarity } \\
\text { Index }\end{array}$ & $\begin{array}{l}\text { Cultural similarity between the region } \\
\text { and neighboring countries }\end{array}$ & $\begin{array}{l}\text { Fifth and sixth } \\
\text { national censuses }\end{array}$ & + \\
\hline $\begin{array}{l}\text { Bilateral Economic } \\
\text { Integration Index }\end{array}$ & $\begin{array}{l}\text { The degree of bilateral free trade } \\
\text { between two countries }\end{array}$ & Value assignment & + \\
\hline $\begin{array}{l}\text { Neighboring country } \\
\text { development strength }\end{array}$ & $\begin{array}{l}\text { The comprehensive economic and } \\
\text { foreign trade development levels of } \\
\text { neighboring countries }\end{array}$ & World Bank & + \\
\hline Market opportunities & $\begin{array}{l}\text { Differences in economic development } \\
\text { between the region and neighboring } \\
\text { countries }\end{array}$ & World Bank & + \\
\hline Favorable Policy Index & $\begin{array}{l}\text { Level of support from national policies } \\
\text { on regional development }\end{array}$ & Value assignment & + \\
\hline Number of ports & The number of ports in the border area & $\begin{array}{l}\text { China's port-of-entry } \\
\text { yearbook }\end{array}$ & + \\
\hline Urbanization rate & Regional urbanization level & $\begin{array}{l}\text { China Statistical } \\
\text { Yearbook }\end{array}$ & + \\
\hline $\begin{array}{l}\text { Secondary and tertiary } \\
\text { industry ratio }\end{array}$ & $\begin{array}{l}\text { Level of off-farm economy in the } \\
\text { region }\end{array}$ & $\begin{array}{l}\text { China Statistical } \\
\text { Yearbook }\end{array}$ & + \\
\hline Transport accessibility & $\begin{array}{l}\text { Level of accessibility of transportation } \\
\text { in the region }\end{array}$ & $\begin{array}{l}\text { Comprehensively } \\
\text { calculated }\end{array}$ & + \\
\hline
\end{tabular}

for Systemic Peace and is based on military conflict between countries and national sovereignty characteristics. The higher the index value, the more fragile the country, and 
the less capacity the country has to resist international conflict and violence. The Cultural Similarity Index is represented by the ratio of minority population shared by the region with neighboring countries over the total population of the border areas (Kuang-Hann, 2011). The bilateral economic integration index is a virtual value (Kuang-Hann, 2011): if both countries involved do not participate in any economic agreement, the variable is assigned a value of 1; if both countries have joined the same economic organizations or agreements (i.e., World Trade Organization (WTO), Regional Trade Agreements (RTAs) or Preferential Trade Arrangements (PTAs)), the variable is assigned a value of 2 ; if both countries are negotiating or if both countries have signed a Free Trade Agreement (FTA), the variable is assigned a value of 4 . The development strengths of neighboring countries are calculated from three representative foreign trade economic indexes: imports of goods and services, exports, and GDP. References for calculating the Favorable Policy Index (Li and Fang, 2014). Reference for calculating the Transport Accessibility Index (Liu and Zeng, 2011). Market opportunity is represented by per capita GDP of neighboring countries/per capita GDP of China's border area.

Using geographical detectors developed by Wang Jingfeng and his team, we calculated the explanatory power for comprehensive measurement level of the geo-economy under the geo-economic influencing factors in the border areas of China. After conducting range standardization for indexes, this study discretized data by means of natural breaks. Geographical detectors include four parts: risk detection, factor detection, ecologic detection, and interaction detection (Wang and $\mathrm{Hu}, 2012$ ). Risk detection is used to explore risk locations, identify the differences between comprehensive evaluation values of the geo-economy under various influencing factors, and also to reveal the factors that significantly influence the highs and lows of the geo-economics. Factor detection is used to identify the factors that can cause the risks. In this study, factor detection is mainly used to measure the explanatory power for geo-economic evaluation values by each influencing factor. Ecologic detection can explain the relative importance of risk factors, compare the explanatory power of different influencing factors, and determine if there are significant differences between these influencing factors. Interaction detection analyzes whether there are influencing factor interactions on geo-economic comprehensive evaluations. Please see related references for methodology (Zhan et al., 2015).

\section{Spatial differences of geo-economics in the border areas of China}

\subsection{Spatio-temporal evolution of geo-economics}

We selected 2000, 2005, 2010 and 2014 as the study years (except for the Tibet Autonomous Region, where the year 2000 data were missing) from which to draw data to calculate the geo-economic comprehensive development levels for 45 prefecture-level cities (areas) in the border areas of China. We then used natural breaks in GIS to classify data and divide geo-economic development levels in border areas into four categories: high level, relatively high level, medium level, and low level, as shown in Figure 2.

Considering the temporal evolution of comprehensive measurement levels, both the development levels of the geo-economy in various areas and the values for each subsystem are increasing year after year. The annual growth rate of the overall evaluation value for comprehensive geo-economic development level in border areas is $8.9 \%$; the annual growth rate 
of the average evaluation value is $8.1 \%$. Under the influence of China's western development policy, economic trade between border areas and neighboring countries has deepened, regional strategic collaboration has been reached, and the comprehensive geo-economic development level has increased rapidly from 2000 to 2010 .

To make the analysis more clear, this study has divided the border areas of China into different regions. We define the border areas in Heilongjinang Province, Jilin Province and Liaoning Province as Northeast China; the border areas of Inner Mongolia (including Jiuquan city in Gansu Province, since they have similar geopolitical environments) as Inner Mongolia area; the border areas of Xinjiang Uygur Autonomous Region and Tibet Autonomous Region by their administrative division as Xinjiang and Tibet respectively; and the border areas in Yunnan Province and Guangxi Zhuang Autonomous Region as Yunnan-Guangxi area.

The comprehensive geo-economic evaluation values of all the areas increased to different degrees. The regions with the highest comprehensive evaluation levels were Mudanjiang city and Fangchenggang city in 2014 and 2000, respectively; the regions with the lowest evaluation levels were Nyingchi Prefecture and Da Hinggan Ling Prefecture in 2014 and 2000, respectively. Compared to all of the border areas, the dominance of Northeast China in geo-economics has decreased gradually. In addition, dominant regions are dispersed significantly in space.

There are significant spatial distribution differences in geo-economic development levels in the border areas of China. By calculating and examining coefficients of variation, we observe that the difference between regions is increasing year after year. Regionally speaking, Mudanjiang had the highest level of geo-economic influence in Northeast China as it has a large market for economic trade with Russia. Currently, three international air routes are in operation between Mudanjiang and Vladivostok, as well as other areas in Russia. As an important border city, Suifenhe is completing its external connection channels to Russia. In addition, Russia boasts abundant mineral resources, low tariffs, a large amount of available labor, and low-priced land. The above factors have all contributed to China's large-scale investments in Russia. Meanwhile, Northeast China has actively exported agricultural products to and promoted agricultural cooperation with Russia.

As the largest industrial city in Inner Mongolia, Baotou has great strength in this regard. Baotou has also been collaborating with Mongolia in energy, crops, and livestock products; both countries benefit greatly from this partnership. In Xinjiang, the Bortala Mongol Autonomous Prefecture had the highest level of geo-economic influence. Xinjiang has a promising prospect in border trade as it has many open ports along its long border line. As the bridgehead of western China's opening, Bortala has been playing a critical role in the import and export channels of the 2nd Eurasian Continental Bridge. Alashankou port has the highest ranking among the national land ports in cargo volume handled, customs revenue, and trade revenue. Moreover, bordering countries display an evident will to collaborate. Central Asia is located inland and mostly dependent on a resource-based economy. As such, the import and export channels have become the lifeline of economic development in this region, and collaboration with neighboring countries is essential for economic development.

In the Yunnan-Guangxi area, Dehong Dai and Jingpo Autonomous Prefecture and Chongzuo city are the top two geo-economic influencers. However, the spatial differences are not 
significant. Although cross border trade was prosperous, there was not a high level of collaboration due to the limited level of economic development in neighboring countries such as Myanmar, Vietnam, and Laos. Due to the improving trade and investment environment in Dehong, infrastructure construction has begun to form in Ruili city, which will lead to the migration of a large number of businessmen, thereby providing a basis for further collaboration in these border areas. As an important channel to connect Southeast Asia with South Asia, Muse has become a prosperous town in northern Myanmar. There is a large potential for cooperation between China and Myanmar, as well as between China and Vietnam. Myanmar and Vietnam also attract many Chinese tourists. Connecting the market of Chinese mainland through southwestern channels is an efficient way to achieve economic prosperity for countries in Southeast Asia. Considering geopolitical strategies, areas that occupy vital communication lines and prosperous border areas usually have prominent advantages for developing their geo-economies. In addition, the dot characteristic of a nation's policies can further strengthen the spatial differences of the geo-economy.

\subsection{Patterns of regional difference of geo-economic development}

According to the index weights, the foreign trade dependence ratio (0.111), import and export trade volume (0.107), and foreign capital reliance (0.103) contribute the most to geo-economic development evaluations in the border areas of China. Geo-economics is related to foreign capital utilization and foreign trade credits, and as such is largely influenced by foreign capital. The ability to utilize foreign capital not only reflects the attraction of foreign assets, but also demonstrates the degree of opening-up and the development of export-oriented economy in local areas. Import and export trade volume represents the trade association degree between border areas and neighboring countries. Export-oriented economic subsystems and foreign capital reliance constitute larger weights, which illustrate that using foreign capitals efficiently is an important part of optimizing the geo-economic environment and promoting the development of an export-oriented economy (Figure 3).

Considering the spatio-temporal evolution of geo-economic subsystems in all areas, the comprehensive development of Northeast China and the Yunnan-Guangxi area is relatively better in 2000; however, their foreign economies present evident spatial differences. Areas with better export-oriented economic development are mainly Mudanjiang city, Dandong city, Dehong Dai and Jingpo Autonomous Prefecture and Fangchenggang city. Common characteristics shared by these cities include a developed border economy and smooth cross-border travel. Under coastal-dominant opening-up development, the export-oriented economy grows more slowly in the inland border areas of China, and only a few areas like Bortala and Hulun Buir have relatively better development. In general, most of the inland border areas have slower socio-economic development.

In 2005, the export-oriented economy of border areas underwent a more rapid development. Bortala in Xinjiang and Mudanjiang in Heilongjiang had the fastest development of geo-economic influence. Meanwhile, Bortala Mongol Autonomous Prefecture and Ili Kazakh Autonomous Prefecture in Xinjiang developed quickly and became important areas for growth of export-oriented economy in border areas. With the advantage of having a vital transportation location in Alataw Pass, Bortala has become an important node for 

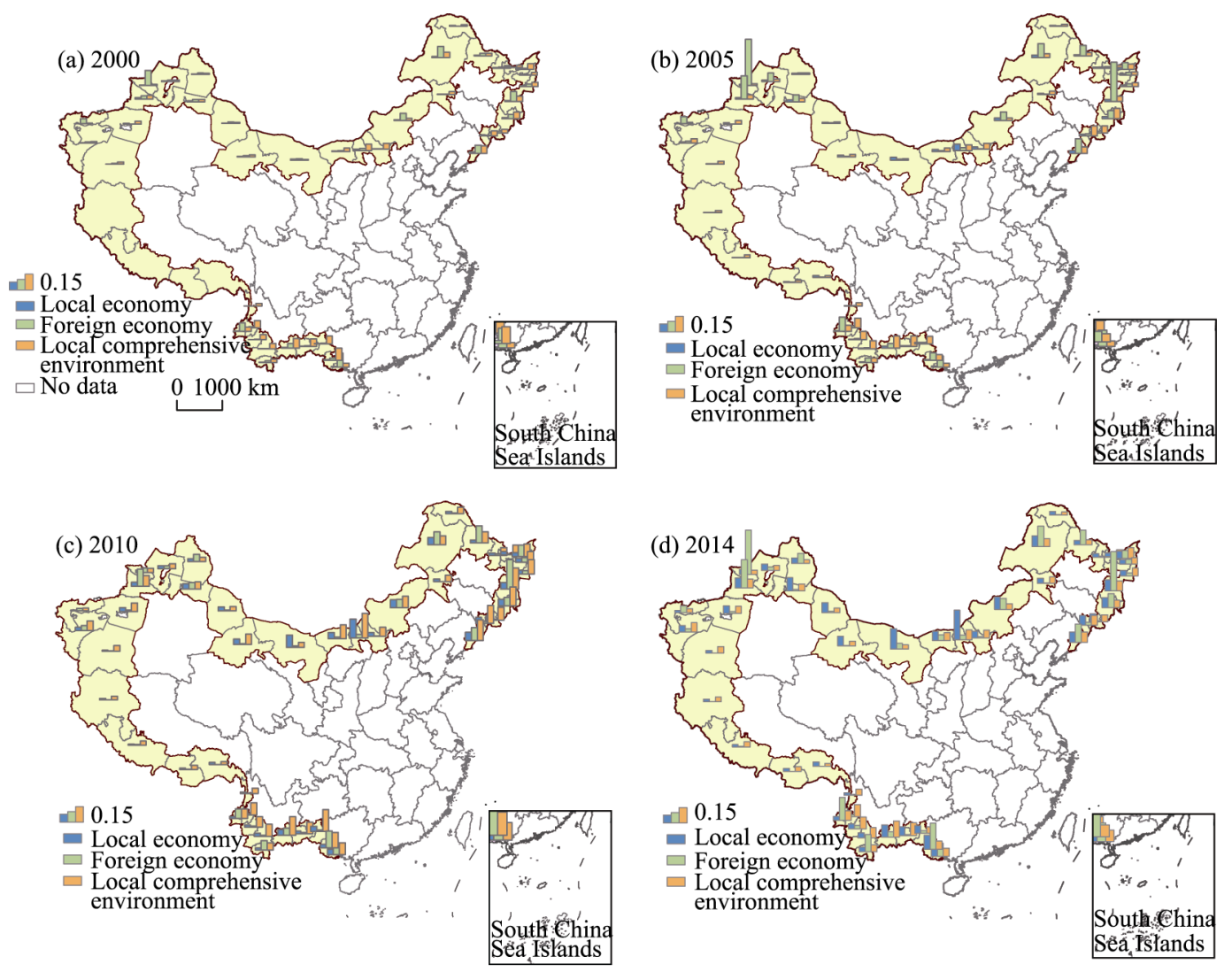

Figure 3 Evaluation of geo-economic subsystems in the border areas of China

opening-up policy and better interaction between China and western countries. Since the second New Eurasion Land Bridge was completed in 1990, and China's role has increased gradually after joining the World Trade Organization (WTO), the export-oriented economy of Bortala has developed at a fast pace. As a vital city for opening-up in Heilongjiang, Mudanjiang faces the Sea of Japan and has smooth foreign trade channels, producing a fertile environment for the development of the export-oriented economy.

In 2010, border areas, especially Northeast China, developed faster; in addition, the local economy and comprehensive development level gradually improved. The cities of Mudanjiang, Heihe, and Dandong have more noteworthy developments in their export-oriented economies. Border areas between China and Russia such as Mudanjiang, Yanbian Korean Autonomous Prefecture, and Heihe have relatively higher overall evaluations. The city of Baotou has the highest development index in Inner Mongolia. However, it does not have substantial geo-economic advantages. The internal differences in geo-economic standing in Xinjiang are decreasing. The import and export trade volume of Bortala is suffering a significant decrease. Although the Ili has better geo-economic conditions, it is still not comparable to coastal cities such as Mudanjiang and Chongzuo. The local comprehensive environment is relatively good in the Yunnan-Guangxi area, which is reflected on the geo-economic development of Fangchenggang city and Dehong prefecture. However, the regions with better geo-economic development are still located in the cities of Chongzuo and 
Baise, which are along the coastal lines. Other cities take fewer advantages of local resources.

The local economy in most regions had rapid growth in 2014. Based on the spatial different pattern in 2010, the export-oriented economy of Bortala and Ili prefectures was developing quickly; these cities became growth poles in 2010.

In general, the internal geo-economic differences in Northeast and Southwest China are relatively small. Border areas between China and Russia, as well as Dandong in Northeast China, are developing strong geo-economic stances. Although China and North Korea share similar cultures, North Korea refuses to implement an open policy. Two-way trade is confined to government procurement with limited trade volume. Thus, the development of geo-economic advantages is restricted. The Yunnan-Guangxi area should take full advantage of its local comprehensive environment and promote its export-oriented economy to accelerate the development of the local economy. The Xinjiang area focuses on the development of areas with greater potential. The Chinese government invests more in the Bortala prefecture, which has allowed it to attain dominance in Inner Mongolia. The differences within Inner Mongolia are mainly reflected by its economic development environments. Baotou city has the best economic strength. Due to relatively low levels of socio-economic and geo-economic development in Mongolia, using Mongolia to connect Russia, Central Asia, and Europe is critical for the export-oriented economy in Inner Mongolia. Constrained by unfavorable topographical conditions, the Tibet area has a small volume of foreign trade, and its indexes are not significant in influencing geo-economics.

\section{Analysis of differentiation of geo-economy in the border areas of China}

\subsection{Analysis of the geo-economic differentiation}

To reveal the influence mechanisms for geo-economics in border areas of China, this study used the geographic detection method to analyze the differentiation in geo-economics, which includes risk detection, factor detection, ecologic detection, and interactive detection.

The results of risk detection indicated that with the significance level set at 0.05 , the factors determining the differentiation of geo-economic development include favorable policy index, transport accessibility, cultural proximity, and bilateral economic integration, which all have a positive influence on geo-economics. Policies favorable for export-oriented economy and strengthened economic interactions with neighboring countries give a strong boost to economic growth in border areas.

The results of factor detection indicate that the favorable policy index has the greatest explanatory power as well as a significant influence on geo-economics. The Favorable Policy Index also serves as a key factor in the promotion of geo-economic development in border areas. The Chinese government has extended favorable policies and increased investment in border areas, which include improving infrastructure such as transportation and building cross-border economic zones. For instance, Horgos Port is improving quickly in its geo-economic standing, economic environment, and urbanization because it is the only city that enjoys the favorable policy of hosting a special economic zone in Horgos along the border area of China-Kazakhstan. Due to the improvement in geo-economic standing and 
economic environment, urbanization in ports is accelerating, and the area of development zones is expanding. With the support of special policies, the Horgos Port is no longer under the governance of Huocheng county and Yili city, but instead under that of Horgos city. This may become the economic zone with the greatest potential in western China.

Bilateral economic integration and the number of ports also have a certain explanatory power (Table 4). In earlier history, China's border opening-up policies were implemented in ports and border cities. As bilateral economic relations have been thriving since the beginning of development in western China, port areas represented by Alataw Pass, Manchuria, and Pingxiang have a great opportunity to further develop. Bilateral free trade with neighboring countries and further opening up has strengthened geo-economic positioning. Meanwhile, similar languages and cultures promoted the cultural exchange environment and bilateral trade. Due to the financial crisis in 2008, the explanatory power of indexes changed in 2010; the transport accessibility and State Fragility Index had relatively high explanatory powers. Border areas that serve as critical connections between China and bordering countries have geo-economic advantages. Areas with limited capacity to resist financial crisis and regions in the China-Myanmar border area have experienced a slower or even negative growth in economic development. Furthermore, the explanatory power of indicators for border areas is experiencing a transition from a single element to multiple factors, and the difference between indicators is decreasing.

Table 4 The explanatory power of influencing factors of the geo-economy in the border areas of China

\begin{tabular}{ccccccccc}
\hline & $\begin{array}{c}\text { State } \\
\text { fragility } \\
\text { index }\end{array}$ & $\begin{array}{c}\text { Cultural } \\
\text { prox- } \\
\text { imity }\end{array}$ & $\begin{array}{c}\text { Bilateral } \\
\text { economic } \\
\text { integration } \\
\text { level }\end{array}$ & $\begin{array}{c}\text { Development } \\
\text { strength of } \\
\text { neighboring } \\
\text { countries }\end{array}$ & $\begin{array}{c}\text { Market } \\
\text { oppor- } \\
\text { tunities }\end{array}$ & $\begin{array}{c}\text { Preferen- } \\
\text { tial policy } \\
\text { index }\end{array}$ & $\begin{array}{c}\text { Number } \\
\text { of ports } \\
\text { of entry }\end{array}$ & $\begin{array}{c}\text { Urbani- } \\
\text { zation } \\
\text { rate }\end{array}$ \\
\hline 2000 & 0.098 & 0.214 & 0.485 & 0.078 & 0.045 & 0.578 & 0.252 & 0.141 \\
2005 & 0.046 & 0.261 & 0.526 & 0.080 & 0.068 & 0.523 & 0.145 & 0.235 \\
2010 & 0.307 & 0.194 & 0.229 & 0.281 & 0.147 & 0.427 & 0.234 & 0.273 \\
2014 & 0.112 & 0.282 & 0.264 & 0.094 & 0.294 & 0.650 & 0.213 & 0.196 \\
\hline
\end{tabular}

Ecological exploration focuses on comparing the impacts of different influencing factors on the explanatory power of geo-economics and determining the relative importance of these factors. Results show that the explanatory power of favorable policy index is significantly larger than other influencing factors, while the difference of explanatory power between other factors is not statistically significant.

Interactive detection analyzes the impact of different factors on the comprehensive evaluation value of geo-economics and determines whether there is any interaction. In the years studied, there are combinations whose explanatory power appears to be more significant and shows non-linear reinforcement after the interaction of different influencing factors. In 2000, 2005, and 2014, most factors are non-linearly strengthened in explanatory power after interactions. In 2010, most factors showed bi-linear strengthening after interactions, indicating that the comprehensive geo-economic level of border areas in 2010 was mainly the result of interactions between the majority of the influencing factors. This is substantiated by the insignificant difference in the explanatory powers of different factors in 2010 . After combining the favorable policy index and other factors such as bilateral economic in- 
tegration level, cultural proximity, traffic flow, and accessibility, the explanatory power is significantly greater than the sum of the explanatory powers of any two factors. In the border areas with sufficient regional development potential and similar culture shared with neighboring countries, conducting bilateral trade negotiations with neighboring countries and implementing regional favorable policies will effectively promote geo-economic development.

\subsection{Analysis of mechanisms of geo-economy in different border areas}

In this study, the regional differentiation characteristics of geo-economics are analyzed using the geographic detection method that includes risk detection, factor detection, ecologic detection, and interactive detection. Another focus of this study is the influencing mechanism of regional geo-economy in border areas (Table 5).

Risk detection: At a significance level of 0.05 , market opportunities, the ratio of secondary to tertiary industry, and transport accessibility have a significant impact in Northeast China. In Inner Mongolia and Tibet, the economic development of neighboring countries plays a critical role in the geo-economic evaluation, while in Xinjiang and Yunnan-Guangxi area the ratio of secondary to tertiary industry is the most important factor. The classification values of other influencing factors did not show significant impacts on the comprehensive evaluation. In Xinjiang, as well as the Yunnan-Guangxi area, the ratio of secondary to tertiary industry is low, which has a more significant impact on the evaluation of geo-economics.

Factor detection: The difference in the explanatory power of regional influencing factors is significant. The geo-economy in Inner Mongolia is greatly affected by neighboring countries, especially with regard to their development. Meanwhile, national vulnerability and cultural proximity also have a strong impact. There is a wide border area between Inner Mongolia and Mongolia. Mongolia is a lower-middle income country, which is located deeply inland, and has a relatively small trade volume of imports and exports. These factors all limit the development of geo-economics in Inner Mongolia. The explanatory power of favorable policy indexes is most significant in Northeast China and Xinjiang. In the context of the "Planning for Revitalization in Northeast China" policy, the number of border economic cooperation zones in this region has increased. Xinjiang has favorable policies that play a crucial role in promoting the development of geo-economics. In Tibet, the development of neighboring countries and bilateral economic integration levels have the greatest explanatory power; these two factors are most important. Measurement results show that the geo-economic environment of the Tibet area is mainly influenced by its neighboring countries. Considering the situation in Tibet, border areas have complex topography and fewer populations; thus there is significant resistance to an export-oriented economy. In addition, neighboring countries such as Pakistan, India and Bhutan have lower levels of economic development and foreign trade. Free trade negotiations between these countries and China are progressing slowly. Both natural conditions and the economic environment have restricted geo-economic development in Tibet. However, under the influence of various factors, there is no large difference in explanatory power in the different indexes in the Yunnan-Guangxi area. The development level of neighboring countries, the cooperative willingness of neighboring countries, and the presence of favorable policies in border areas all play important roles in the development of geo-economics. 
Table 5 The explanatory power of the influencing factors in geo-economy in the border areas of China

\begin{tabular}{|c|c|c|c|c|c|c|c|c|c|c|}
\hline & $\begin{array}{c}\text { State } \\
\text { Fragility } \\
\text { Index }\end{array}$ & $\begin{array}{l}\text { Cultural } \\
\text { proximity }\end{array}$ & $\begin{array}{c}\text { Bilateral } \\
\text { economic } \\
\text { integration } \\
\text { level }\end{array}$ & $\begin{array}{l}\text { Develop- } \\
\text { ment of } \\
\text { neighbor- } \\
\text { ing coun- } \\
\text { tries }\end{array}$ & $\begin{array}{c}\text { Market } \\
\text { opportu- } \\
\text { nities }\end{array}$ & $\begin{array}{l}\text { Favor- } \\
\text { able } \\
\text { Policy } \\
\text { Index }\end{array}$ & $\begin{array}{l}\text { Number } \\
\text { of ports } \\
\text { of entry }\end{array}$ & $\begin{array}{c}\text { Urbani- } \\
\text { zation } \\
\text { rate }\end{array}$ & $\begin{array}{c}\text { Ratio of } \\
\text { secondary } \\
\text { to tertiary } \\
\text { industry }\end{array}$ & $\begin{array}{c}\text { Trans- } \\
\text { portation } \\
\text { accessi- } \\
\text { bility }\end{array}$ \\
\hline Inner Mongolia & 0.484 & 0.420 & 0.346 & 0.489 & 0.326 & 0.073 & 0.163 & 0.378 & 0.360 & 0.132 \\
\hline $\begin{array}{l}\text { Northeast } \\
\text { China }\end{array}$ & 0.201 & 0.255 & 0.398 & 0.301 & 0.181 & 0.640 & 0.302 & 0.304 & 0.249 & 0.393 \\
\hline Xinjiang & 0.106 & 0.185 & 0.278 & 0.305 & 0.119 & 0.502 & 0.290 & 0.222 & 0.140 & 0.226 \\
\hline Tibet & 0.085 & 0.100 & 0.756 & 0.934 & 0.314 & 0.083 & 0.112 & 0.097 & 0.111 & 0.111 \\
\hline $\begin{array}{l}\text { Yunnan- } \\
\text { Guangxi area }\end{array}$ & 0.477 & 0.176 & 0.402 & 0.434 & 0.126 & 0.441 & 0.267 & 0.230 & 0.330 & 0.234 \\
\hline
\end{tabular}

Considering the regional differences in explanatory power of influencing factors, the geoeconomics of border areas are mainly affected by two elements: favorable Chinese policies for border areas, and the development level of neighboring countries, including their willingness to conduct bilateral trade with China. The Inner Mongolia and Tibet areas are mainly influenced by neighboring countries, while Northeast China and Xinjiang are mainly affected by Chinese policies; the Yunnan-Guangxi area is influenced by a combination of these factors.

Ecologic detection: The explanatory power of different influencing factors is not significantly different in Inner Mongolia and Xinjiang. The state fragility index in the Yunnan-Guangxi area has a significant impact since this area neighbors Myanmar, Laos and Vietnam, and is strongly affected by these countries' unstable geopolitical environments. The favorable policy index in Northeast China and the development of neighboring countries in Tibet have significantly higher explanatory powers than other indexes. The Favorable Policy Index is more significant, which indicates that human factors cannot easily change the geo-economic development under different country power levels.

Interactive detection: The explanatory power of a combination of different factors is significantly greater than that of any single factor in all areas. Inner Mongolia, Northeast China, Tibet, and the Yunnan-Guangxi area depict a bilinear increase in explanatory power, while Xinjiang exhibits a non-linear increase. Thus, the geo-economies of border areas are mainly affected by integrating factors, especially the nation's internal and external factors.

\section{Conclusions and discussion}

Under economic globalization, different regions are interacting more closely, and geopolitical risks are becoming increasingly complex. The border areas are the core catalyst for interactions between China and its neighboring countries, and also important regions with high population density and industry as well as large economies. This study attempts to describe the spatio-temporal differentiation of the geo-economy in the border areas of China under globalization, and analyzes the mechanism of differentiation in the geo-economy using geographic detectors. The entropy method is used to conduct a comprehensive evaluation of the geo-economy, which demonstrates that export-oriented economies have become the main geo-economic characteristics of Chinese border areas. From 2000 to 2014, 
geo-economics has driven the overall development and opening up in the border areas of China. The absolute dominance of Northeast China in geo-economics has gradually weakened over time, and the importance of Xinjiang has become more evident. The border areas which developed and opened up first, such as the international cooperation demonstration areas and the key development and opening-up pilot zones, promoted the formation of growth poles in the border areas and formed the differentiated spatial structure. Analysis of the mechanism of geo-economics through the use of geographic detectors shows that export- oriented policy, bilateral economic integration level, and market opportunities play a crucial role in influencing geo-economics in the Chinese border areas. Under complex geographic conditions, export-oriented policy has a significant effect on the polarization of border areas.

The developmental strategy of spatial differentiation in border areas has further strengthened the spatial difference in geo-economics. In the context of the "Belt and Road Initiative", the development and opening up of western China has become an evident trend. Northwest China, primarily Xinjiang, is progressively exhibiting its strategic dominance. The geo-economics of this region is rapidly growing, and is gradually becoming the new economic growth pole in the border areas of China. The study of the mechanism of differentiation in geo-economics shows that geo-economics is heavily influenced by geopolitics. The development of neighboring countries, national vulnerability, and other factors further influence economic development and foreign trade in border areas. Meanwhile, under the guidance of certain policies, geo-economic development is useful in reducing border conflicts and improving border security. Guided by border opening-up policies, the economy grows rapidly in the northwest and southwest border areas of China. These results indicate that the special policy areas, such as the border cooperation areas and the key development and opening-up zones, have a significant impact on the geo-economic growth of border areas. Accordingly, the application of such policies in more places should be encouraged in the future. Therefore, strengthening the geo-economic position of border areas which have favorable locations, good foundations, and a stable surrounding environment is helpful for building a safe and stable geo-economic space, improving the bilateral economic trade level, and maintaining the economic and political environment in neighboring countries as well as in China. In addition, this would assist in building a solid foundation to support the maintenance of overall security and stability in China.

Compared to the traditional research on borders that is mainly based on the economy and society of border areas, geo-economics, as the latest trend in the study of geopolitics, contains an inductive method to investigate the spatial characteristics of economic factors at multiple scales. First, geo-economics focuses on studying the problems and phenomena of an export-oriented economy under globalization. It is no longer limited to the factor explanation and spatial structure of regional development and the current status. Further research needs to place the region into a larger scale in order to carry out systematic analyses. The geo-economic theory needs to take into account both the domestic and international benefit structures with the characteristics of hierarchy and complexity. Based on the study of border areas, the geopolitical condition of neighboring countries, policy stability, and international trade environment all affect the development of border areas. The author believes that this approach helps to break the constraints of western theory, to gain a deeper understanding of the key elements of geo-economic society in different regions and the spatial relations be- 
tween these elements, and also helps to reveal the uniqueness of Chinese border areas. It is highly important for academics and the Chinese government to explore the development level, process of evolution, and driving force behind geo-economics. It serves China's "Belt and Road Initiative" and "Comprehensive Border Opening-up" strategy. It is also valuable in the promotion of regional development, and provides the theoretical basis and geographic support for carrying out geo-economic cooperation with neighboring countries. This is an early-stage study that lacks consideration in the design of technical methods and the selection of geo-economic indexes. For example, the entropy weighting method determines the weight based on the degree of discretization of data. This is objective, but the weight may be inconsistent with regard to the importance of the index. In addition, geographic detectors can only calculate discrete data, which lowers the internal difference in sampled data. Moreover, interactive detection can obtain the results of the interaction between any two factors; however, it cannot analyze the interactions between multiple factors. These issues need to be resolved through the use of new perspectives and methods.

\section{References}

Brunet-Jailly E, 2005. Theorizing borders: An interdisciplinary perspective. Geopolitics, 10(4): 633-649.

Buckley P J, Clegg L J, Cross A et al., 2007. The determinants of Chinese outward foreign direct investment. Journal of International Business Studies, 38: 499-518.

Chen Mingxing, Lu Dadao, Zhang Hua, 2009. Comprehensive evaluation and the driving factors of China's urbanization. Acta Geographica Sinica, 64(4): 387-398. (in Chinese)

Chou Kuang-Hann, Chen Chien-Hsun, Mai Chao-Cheng, 2011. The impact of third-country effects and economic integration on China's outward FDI. Economic Modelling, 28: 2154-2163.

Cui Jun, 2004. A research on geo-economic cooperation in Northeast Asia [D]. Changchun: Jilin University. (in Chinese)

Ding Hongjian, Yu Zhenguo, 2008. An analysis of the match between the direction and intensity of urban economic contact and the geoeconomic relationship. China Soft Science, (3): 44-51. (in Chinese)

Feng Guoqun, Ding Sibao, 2005. Retrospect and prospect of the cross-border cooperation study. World Regional Studies, 14(1): 53-59. (in Chinese)

Gao Jiaxiang, 2008. Geo-economy and China's geo-strategy in Central Asia [D]. Lanzhou: Northwest Normal University. (in Chinese)

Gao Shuqin, 2009. The factor 'Natural Resources' in the transformation of global geopolitics and geo-economy. Resources Sciences, 31(2): 343-351. (in Chinese)

Hanson G H, 1998. Regional adjustment to trade liberalization. Regional Science and Urban Economics, 28: 419-444.

$\mathrm{Hu}$ Zhiding, Ge Yuejing, Bao Jie et al., 2013. The spatial pattern and differentiation laws of geo-setting in South Asia. Scientia Geographica Sinica, 33(6): 685-692. (in Chinese)

Huang Hui, 2011. A research on geo-economic cooperation of China and its neighbors [D]. Changchun: Northeast Normal University. (in Chinese)

Jin Fenghua, Du Jizhong, 2004. Measurement and analysis on the economic relations of the similar regional origin in Yangtze Delta. East China Economic Management, 18(1): 4-6. (in Chinese)

Li Guangdong, Fang Chuanglin, 2014. Quantitative measure and influencing mechanism of land intensive use in China at the county level. Acta Geographica Sinica, 69(12): 1739-1752. (in Chinese)

Li Hong, 2008. Border Economy: The Entry Point of the Regional Cooperation between China and ASEAN. Beijing: Zhonghua Book Company. (in Chinese)

Li Peng, 2006. On the cooperation development of geoeconomic regions and its practice tactics adjustment: Taking the analysis of cooperation development of geoeconomic regions between China and ASEAN as an example. Economic Geography, 26(2): 186-191. (in Chinese) 
Li Zheng, Chen Cai, Xiong Liran, 2014. An analysis on the theory origin and development vein of geo-economics abroad. World Regional Studies, 23(1): 10-18. (in Chinese)

Liu Chuanming, Zeng Juxin, 2011. The calculating method about the comprehensive transport accessibility and its correlation with economic development at country level: The statistical analysis of 79 counties in Hubei Province. Geographical Research, 30(12): 2209-2221. (in Chinese)

Liu Yuanyuan, Tu Jianjun, 2011. Study on the geo-economic relations of Central Plains Economic Zone. Areal Research and Development, 30(6): 156-159. (in Chinese)

Lu Dadao, Du Debin, 2013. Some thoughts on the strengthening of geopolitical and geo-economic studies. Acta Geographica Sinica, 68(6): 723-727. (in Chinese)

Luo Huasong, Li Feng, 2010. An analysis of the optimal cooperation model of Yunnan multilateral industrial cooperation. Journal of Yunnan Normal University (Philosophy and Social Sciences Edition), 42(2): 65-71. (in Chinese)

Luttwak E N, 1990. From geopolitics to geoeconomics: Logic of conflict, grammar of commerce. The National Interest, 20(3): 17-23.

Newman D, Paasi A, 1998. Fences and neighbors in the postmodern world: Boundary narratives in political geography. Progress in Human Geography, 22(2): 186-207.

Nye J, 2004. Soft Power: The Means to Success in World Politics. Public Affairs.

Pan Zhongqi, Huang Renwei, 2008. Geo-economic strategies of China. Journal of Tsinghua University (Philosophy and Social Sciences), 23(5): 116-122. (in Chinese)

Parker G, 1998. Geopolitics: Past, Present and Future. London: Pinter.

Ratti R, Reichman S, 1993. Theory and Practice of Transborder Cooperation. Verlag Helbing \& Lichtenhahn, Basel und Frankfurt am Main.

Sit V F S, 1998. Hong Kong's "transferred" industrialization and industrial geography. Asian Survey, 38(9): 880-904.

Sklair L, 1993. Assembling for Development: The Maquila Industry in Mexico and the US. San Diago: Center for US-Mexico Studies.

Song Tao, Liu Weidong, Li Le, 2016. International research on the border regions with a geopolitical perspective and revelation. Progress in Geography, 35(3): 276-285. (in Chinese)

Song Tao, Lu Dadao, Liang Yi et al., 2016. Research progress of international geopolitics, 1996-2015. Acta Geographica Sinica, 71(4): 551-563. (in Chinese)

$\mathrm{Su}$ X B, 2012. Rescaling the Chinese state and regionalization in the Great Mekong Subregion. Review of International Political Economy, 19(3): 501-527.

Tang Xueqiong, Yang Qianhao, Qian Junxi, 2016. Meanings and practices of borders from the perspective of cross-border mobility: A case study of village X, Hekou, Yunnan at the Sino-Vietnamese borderlands. Geographical Research, 35(8): 1535-1546. (in Chinese)

Venables A J, 1996. Equilibrium locations of vertically linked industries. International Economic Review, 37(2): 341-359.

Wang J F, Hu Y, 2012. Environmental health risk detection with GeogDetector. Environmental Modeling \& Software, 33: 114-115.

Wang Limao, Li Hongqiang, 2009. Cooperation and competition of oil and gas resources between China and its neighboring countries and its impacts on geopolitics. Resources Sciences, 31(10): 1633-1639. (in Chinese)

Wen Zhihong, 1998. Distance analysis: A method for evaluating geo-economic relations. Statistics \& Decision, (1): $8-10$.

Xiong Wen, Wang Zheng, 2012. New geopolinomic frame and economic crisis. World Regional Studies, 21(4): 1-12. (in Chinese)

Yang Wenlong, Du Debin, Liu Chengliang et al., 2016. Study on the spatial-temporal evolution and internal mechanism of geo-economic connections of China. Acta Geographica Sinica, 71(6): 956-969. (in Chinese)

Yu Guozheng, Fan Hua, 2009. On building a new subject: Geo-geography. World Regional Studies, 18(3): 146-153. (in Chinese)

Zhan Dongsheng, Zhang Wenzhong, Yu Jianhui et al., 2015. Analysis of influencing mechanism of residents' livability satisfaction in Beijing using geographical detector. Progress in Geography, 34(8): 966-975. (in Chinese) 